\title{
Secondary Chronic Respiratory Acidosis in a Dog Following the Cervical Cord Compression by an Intradural Glioma.
}

\author{
Yasushi HARA $^{1)}$, Yoshinori NEZU ${ }^{1)}$, Yasuji HARADA ${ }^{2)}$, Daisuke HASEGAWA ${ }^{3)}$, Michio FUJTA ${ }^{3)}$, Hiromitsu ORIMA ${ }^{3)}$ \\ and Masahiro TAGAWA ${ }^{1)}$ \\ ${ }^{1)}$ Divisions of Veterinary Surgery and ${ }^{3)}$ Veterinary Radiology, School of Veterinary Medicine, Nippon Veterinary and Animal Science \\ University, 1-7-1 Kyonan-cho, Musashino-shi, Tokyo 180-8602 and ${ }^{2}$ Institute for Frontier Medical Sciences, Kyoto University, 53 \\ Kawahara-cho, Shogoin, Sakyo-ku, Kyoto 606-8397, Japan
}

(Received 27 December 2001/Accepted 21 May 2002)

ABSTRACT. An intradural tumor in the upper cervical region was found in a dog with quadriparesis and chronic respiratory acidosis. Surgical removal of the tumor in the atlas and intraoperative radiotherapy were attempted. The tumor was histologically diagnosed as a neural glioma. A preoperative acid-base disturbance was dramatically improved after surgery. The clinical changes appeared in this case suggest that compression of the spinal cord at this region may cause paralysis of the respiratory muscles and secondarily result in chronic respiratory acidosis following the respiratory insufficiency.

KEY WORDS: acidosis, canine, tumor.

J. Vet. Med. Sci. 64(9): 863-866, 2002

Neoplasms of the spinal cord and vertebrae in the dog are classified into three types, which are dependent on the developmental location: extradural, intradural/extramedullary, and intramedullary $[6,9]$. Clinical problems relating to tumors occurring at these regions usually consist of pain and myelopathy that includes sensory and motor nerve systems at the site involved [6, 8-11]. Tumors that develop near the upper cervical vertebral area are known to result in cervical pain, paresis, or paralysis of the fore- and hind-legs. Respiratory abnormality/insufficiency in dogs with cervical tumors have been described in only a few studies $[12,13]$. However, the development of chronic respiratory acidosis due to chronic ventilatory insufficiency has not been documented in detail. Moreover, serial arterial blood gas analyses during the perioperative period have not been reported in such cases to date. We report a case in which chronic respiratory acidosis regressed after the surgical removal of an intradural tumor in the first cervical vertebral region.

An 11-year-old male mongrel dog, weighing $12.6 \mathrm{~kg}$, lost conscious proprioception of its fore- and hind-legs on the right side. The dog developed gait ataxia 58 days prior to presentation to the Veterinary Medical Teaching Hospital of Nippon Veterinary and Animal Science University. At first examination, the dog was in the recumbent position and unable to stand on its legs. Neurological examination revealed a normal level of consciousness, intact cranial nerves, and appropriate sensory responses to deep pain in all four legs. Voluntary urination was possible. The condition was judged as quadriparesis with upper motor neuron signs in all legs. Chest radiography, electrocardiography, complete blood cell count, and biochemical examination revealed no other abnormalities.

Based on these findings, a transversal myelopathy of the upper cervical region was suspected. Plain radiography, myelography (MG) and computed tomography after myelography (CTM) of the cervical vertebrae were performed under general anesthesia [7]. Plain radiographs disclosed no abnormality, but MG revealed swelling of the spinal cord at the atlas. Moreover, the transversal image at this region by CTM disclosed a configurational irregularity of the spinal cord (Figs. 1 and 2). In examination of the cerebrospinal fluid, abnormal cells were not detected, but the protein concentration was markedly high $(234.0 \mathrm{mg} / \mathrm{d} l)$. The diagnosis of an intradural tumor was established on the basis of the above clinical findings.

The clinical symptoms in this case progressed with time. On the 69th day after onset, voluntary urination became impossible. The four legs were completely paralyzed, and a respiratory abnormality appeared. Inspiration and expiration were both shallow, and the dog manifested an exertional paradoxical pattern of respiration. By performing arterial blood gas analyses at regular intervals, respiratory

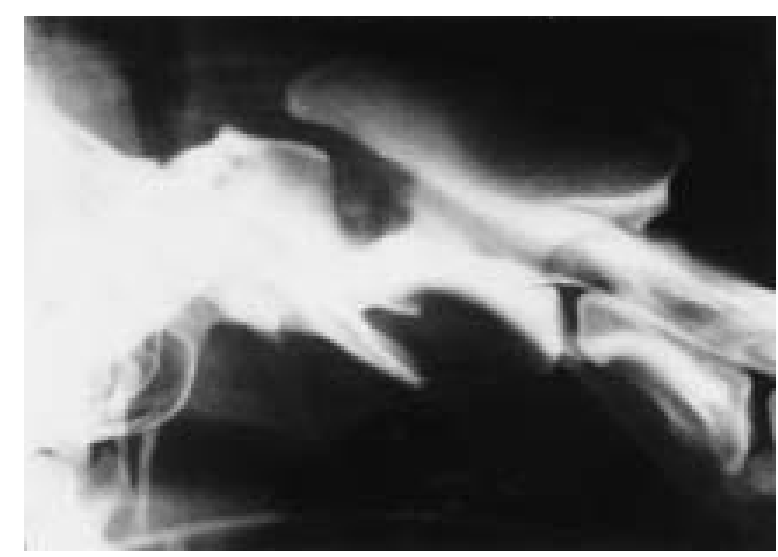

Fig. 1. Lateral myelogram in the area of upper cervical vertebrae in this case. The dorsal and ventral lines of contrast medium were not clearly observed in the area of the atlantoaxial joint, suggesting swelling of the spinal cord. 


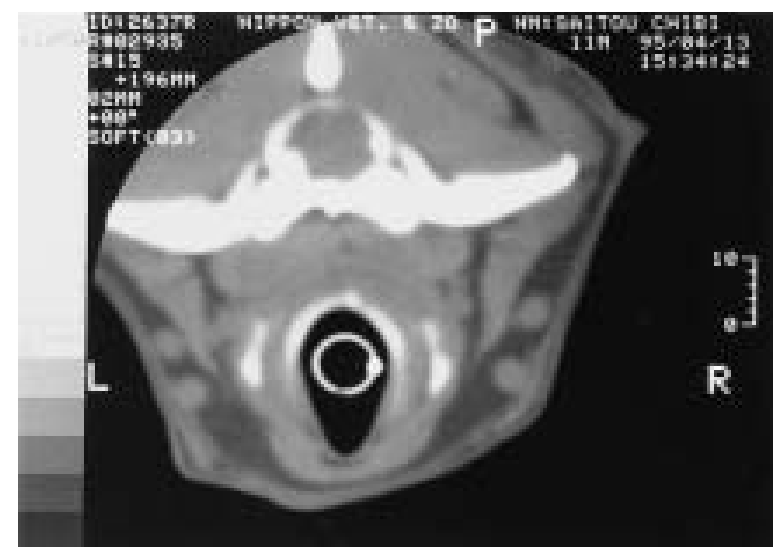

Fig. 2. Transversal image by computed tomography after myelography (CTM) at the atlas. The CTM image disclosed a configurational irregularity of the spinal cord, suggesting the intradural tumor.

acidosis progressed on the 85 th day. The arterial carbon dioxide partial pressure $\left(\mathrm{PaCO}_{2}\right)$, arterial oxygen partial pressure $\left(\mathrm{PaO}_{2}\right)$, arterial oxygen saturation $\left(\mathrm{SaO}_{2}\right)$, and $\mathrm{pH}$ showed $52.6 \mathrm{mmHg}, 69.9 \mathrm{mmHg}, 93.6 \%$, and 7.38, respectively. Surgical decompression of the spinal cord was conducted on the 90th day.

The dog was premedicated with diazepam $(0.2 \mathrm{mg} / \mathrm{kg}$, im) and butorphanol $(0.2 \mathrm{mg} / \mathrm{kg}$, iv $)$. General anesthesia was induced using sodium thiopental $(20 \mathrm{mg} / \mathrm{kg}$, iv), and maintained using isoflurane and oxygen. In consideration of possible elevation of the intracranial pressure due to hypercapnia, the end-tidal carbon dioxide partial pressure $\left(\mathrm{EtCO}_{2}\right)$ was continuously monitored and maintained at 25$30 \mathrm{mmHg}$. Respiration was completely controlled with a ventilator. The animal was positioned in ventral recumbency with extension of the neck. Dorsal laminectomy of the atlas and the cranial half of the axis were performed for approach to the spinal canal. Upon incision of the dura mater and exposure of the spinal cord, a swollen mass (approximately $2 \mathrm{~cm}$ in diameter) was found locally compressing the right side of the spinal cord. The boundary between the spinal cord and the mass was relatively welldefined. The mass was surgically resected. Since the atlantoaxial ligament was resected for approach to the spine, reinforcement was introduced in consideration of the instability of the spine between the atlas and axis. Namely, external skeletal fixation with half-pins was adapted dorsally into the wing of atlas and the vertebral body of axis. The resected tumor was histologically diagnosed as a neural glioma (Fig. 3). Intraoperative irradiation (30 Gy) was carried out during exposure of the spinal cord [4]. Sixty days after surgery, bidirectional (dorsal and lateral) irradiation was performed twice a week for 11 weeks for a total of 21 days (each dose $3 \mathrm{~Gy}$, total dose $42 \mathrm{~Gy}$ ).

Respiration improved immediately after surgery. This was soon followed by a decrease in $\mathrm{PaCO}_{2}$ and increase in $\mathrm{PaO}_{2}$ and $\mathrm{SaO}_{2}$. The dog experienced gradual restoration of

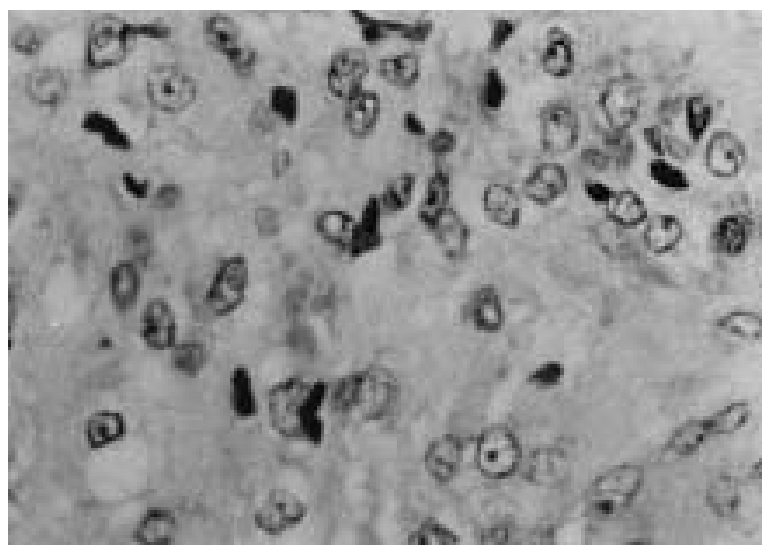

Fig. 3. Histology in the mass removed by surgery. The tumor cells show considerable cellular pleomorphism and nuclear atypia.

voluntary movement of all four legs. On the 63rd day after surgery, the dog was well enough to stand on his legs by himself and walk around freely. Follow-up was continued after discharge from the hospital, but the dog developed a respiratory abnormality on the 144th day after surgery and died suddenly on the 147th day. Postmortem autopsy was not performed, and the cause of death was unknown.

Arterial blood gas analyses were regularly performed from 20 days before to 8 days after surgery using femoral artery samples. Respiration and blood gases began to improve immediately after surgery (Fig. 4). Preoperatively, the $\mathrm{PaO}_{2}$ ranged from 69.3 to $80.5 \mathrm{mmHg}$ and $\mathrm{PaCO}_{2}$ from 38.0 to $52.6 \mathrm{mmHg}$. Especially, respiratory acidosis developed 5 days before surgery. Postoperatively, the $\mathrm{PaO}_{2}$ ranged from 85.2 to $105.8 \mathrm{mmHg}$ and the $\mathrm{PaCO}_{2}$ from 26.2 to $43.5 \mathrm{mmHg}$. All parameters recovered to within normal levels. It appears that the return of blood gas parameters to normal levels was attributed to the recovery of breathing function. This resulted from decompression of the spinal cord and improved function of the reticulospinal tracts. It is known that the neurons of the medullary respiratory center enter the spinal cord via the reticulospinal tracts. This gives rise to the phrenic nerve through segments 5 to 7 of the cervical spinal cord. The reticulospinal tracts also give rise to the neurons that innervate the intercostal muscles via the segmental intercostal nerves [3]. The blood $\mathrm{pH}$ remained within almost normal levels prior to surgery, although the $\mathrm{PaCO}_{2}$ was clearly increased. Respiratory acidosis is classified into acute respiratory acidosis and chronic respiratory acidosis [1,2]. In the former, the increased production of $\mathrm{H}^{+}$ is chemically buffered without compensation by the kidney. In the latter, the kidney exercises a compensatory action. These can be differentiated by the increment of $\mathrm{HCO}_{3}^{-}$in response to the increase in $\mathrm{PaCO}_{2}$. In chronic respiratory acidosis, $\mathrm{HCO}_{3}{ }^{-}$is known to increase by the compensatory mechanism of $0.34-0.39 \mathrm{mEq} / \mathrm{l}$ for every $1 \mathrm{mmHg}$ increase in $\mathrm{PaCO}_{2}$. In acute respiratory acidosis, it is known to increase by $0.15 \mathrm{mEq} / \mathrm{l}$. In the present case prior to surgery, 

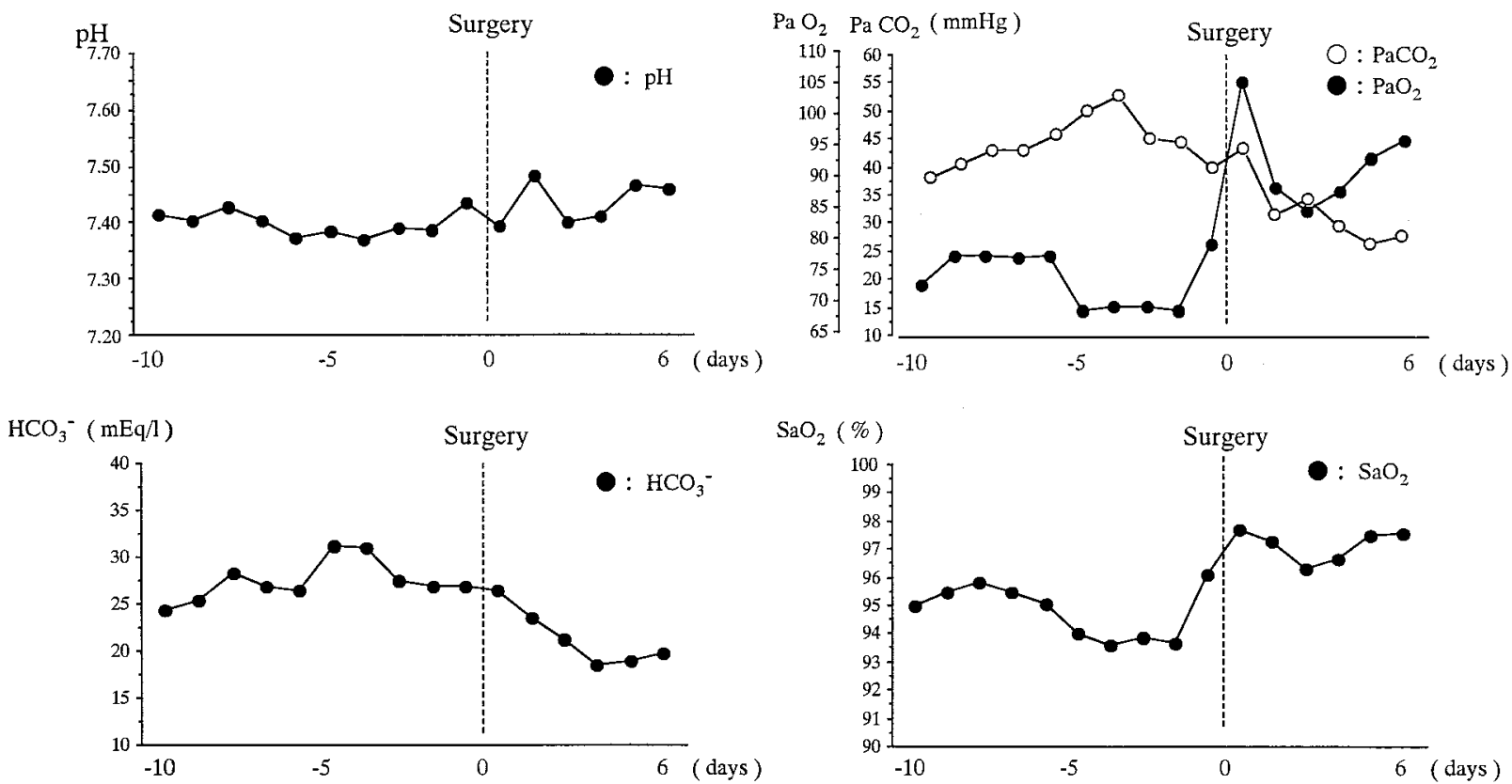

Fig. 4. Changes in acid-base parameters during the clinical course. In the present case prior to surgery, the $\mathrm{HCO}_{3}{ }^{-}$was found to be increased by $0.45 \mathrm{mEq} / l$ for every $1 \mathrm{mmHg}$ increase in the arterial carbon dioxide partial pressure $\left(\mathrm{PaCO}_{2}\right)$. These findings suggested that respiratory acidosis accompanied with mild metabolic alkalosis might have been present before surgery. After surgical removal of the intradural mass, a preoperative acid-base disturbance was dramatically improved.

the $\mathrm{HCO}_{3}{ }^{-}$was found to be increased by $0.45 \mathrm{mEq} / \mathrm{l}$ for every $1 \mathrm{mmHg}$ increase in $\mathrm{PaCO}_{2}$. The $\mathrm{PaCO}_{2}$ and $\mathrm{HCO}_{3}^{-}$ varied in a parallel fashion before and after surgery in this case. These findings suggest that respiratory acidosis in this case was corrected through the compensatory mechanism, namely by the discharge of $\mathrm{H}^{+}$and reabsorption of $\mathrm{HCO}_{3}{ }^{-}$in renal tubular cells. It was also suggested that an accompanied mild metabolic alkalosis might have been present before surgery. This was because the increment of preoperative $\mathrm{HCO}_{3}^{-}$was over the compensatory limit in the kidney. However, the cause of metabolic alkalosis could not be detected. Moreover, the mild increase of blood $\mathrm{pH}$ after surgery was possibly attributed to the decrease of postoperative $\mathrm{PaCO}_{2}$ and the effect of the compensatory mechanism for chronic respiratory acidosis.

Tumors of the spinal cord and vertebrae are classified by the sites of development into three types [6,9]. Gilmore reported that the rates of clinical progression differed with the sites of development [6]. In this case, it was impossible to determine whether the primary site of development at the atlas was from the intradural/extramedullary or the intramedullary region. Judging from the relatively slow rate of progression and from the findings at the local site during surgery, the intradural/extramedullary region was considered likely to be the precise site of development.

Many studies have reported on canine spinal neoplasms by describing clinical cases, radiological features, or pathological classifications. A variety of clinical symptoms associated with myelopathy of the upper cervical region have been described in clinical case reports [5, 10, 11, 14]. A case with chronic respiratory acidosis, such as the one presented here, has not been reported to date. The series of clinical changes seen in this case suggest the sequelae of intradural tumors that develop in the first cervical vertebra. Specifically, tumor compression of the spinal cord at this region causes paralysis of the respiratory muscles and results in chronic respiratory acidosis secondary to respiratory insufficiency.

\section{REFERENCES}

1. Adams, L. G. and Polzin, D.J. 1989. Vet. Clin. North. Am. 19: 307-326.

2. Autran de Morais, H. S. and DiBartola, S. P. 1991. Emerg. Crit. Care 1: 39-49.

3. Beal, M.W., Paglia, D.T., Griffin,G.M., Hughes, D. and King, L.G. 2001. J. Am. Vet. Med. Assoc. 10: 1598-1602.

4. Bell, F. W., Feeney, D. A., O'Brien, T. J., Caywood, D. D. and Hultgren, B. D. 1992. J. Am. Anim. Hosp. Assoc. 28: 318-322.

5. Fingeroth, J. M., Prata, R. G. and Patnaik, A. K. 1987. J. Am. Vet. Med. Assoc. 6: 720-726.

6. Gilmore, D. R. 1983. J. Am. Anim. Hosp. Assoc. 19: 10091014.

7. Hara, Y., Tagawa, M., Ejima, H., Orima, H. and Fujita, M. 1994. J. Vet. Med. Sci. 56: 791-794.

8. Heyman, S. J., Diefenderfer, D. L., Goldschmidt, M. H. and Newton, C. D. 1992. Vet. Surg. 21: 304-310.

9. Jeffery, N. D. 1995. pp. 128-137. In: Handbook of Small Animal Spinal Surgery (Jeffery, N. D. ed.), W. B. Saunders Company Ltd., London. 
10. Luttgen, P. J. 1992. Vet. Clin. North. Am. 22: 973-984.

11. Morgan, J. P., Ackerman, N., Bailey, C. S. and Pool, R. R. 1980. Vet. Radiol. 21: 197-212.

12. Prata, R. G. 1977. Vet. Clin. North. Am. 7: 165-185.
13. Waters, D. J. and Hayden, D. W. 1990. J. Vet. Intern. Med. 4: 207-215.

14. Wright, J. A., Bell, D. A. and Clayton-Jones, D. G. 1979. J. Small Anim. Pract. 20: 461-472. 